\title{
APLICAÇÃO DA METODOLOGIA MASP PARA REDUÇÃO DE PERDAS DE INSUMO NA PRODUÇÃO DE ATOMATADOS: UM ESTUDO DE CASO EM UMA INDÚSTRIA ALIMENTÍCIA
}

\author{
Ana Caroline Lins de Oliveira (UNIFAVIP) carollynelins22@gmail.com \\ Giseli Cezina Silva (UNIFAVIP) giselicezina@gmail.com \\ Heloísa Horranna Santos Galvão (UNIFAVIP) galvaoheloisa@ hotmail.com \\ Medianeles da Silva Bezerra (UNIFAVIP) midianeles@ hotmail.com \\ Meyrianne Barros da Mota (UNIFAVIP) meyrianne.motta@outlook.com
}

\section{Resumo}

Atualmente a grande concorrência nas empresas instigou a necessidade de uma nova visão, onde a qualidade nos processos está diretamente ligada ao aumento da produtividade da empresa, aumentando assim os seus ganhos. A partir do pressuposto, o presente artigo tem como objetivo aplicar ferramentas da área de gestão da qualidade, analisando a aplicação das mesmas, na redução de perdas de matéria prima na linha de atomatados. $\mathrm{O}$ estudo de caso feito em uma empresa de médio porte do ramo alimentício, a partir da utilização do método MASP, uma ferramenta estratégica com o intuito de atacar e solucionar os problemas encontrados, buscando diversas ferramentas da qualidade. Ao decorrer da evolução do estudo de caso foram verificadas mudanças significativas na empresa, demonstrando o valor do método MASP e das ferramentas da qualidade neste cenário.

Palavras-chave: Ferramentas da qualidade. MASP. Redução de perdas. Gestão da qualidade.

\section{Introdução}

"A indústria de alimentos é a maior do País. Processa 58\% de tudo o que é produzido no campo, reúne mais de 37 mil indústrias que geram 1,6 milhão de empregos diretos e formais" (ABIA, 2019, p.07).

Um desses alimentos é o tomate, uma das hortaliças mais cultivadas no mundo. Sua utilização engloba dois segmentos distintos, o denominado tomate mesa utilizado para consumo do produto fresco (in natura) e o tomate industrial (destinado às indústrias de processamento para produção de polpas, molhos, temperos, sopa em pó, entre outros). Ultimamente o tomate 
industrial devido a uma série de fatores vem ganhando destaque devido ao aumento da demanda por refeições fora de casa e de alimentos que possam ser feitos de forma mais ágil (EMBRAPA, 2019).

Os alimentos brasileiros são exportados para mais de 180 países constituindo assim o segundo maior exportador de alimentos industrializados do mundo. $\mathrm{O}$ faturamento das indústrias representou cerca de 9,6\% do PIB do Brasil em 2019 e o setor contribuiu com 67\% do saldo geral da balança comercial brasileira, gerando um superávit de US\$28,8 bilhões. (ABIA, 2019)

A concorrência, a necessidade de sobreviver, prosperar e se tornarem competitivas, levou as empresas a terem a necessidade de aprender a movimentar-se em ambientes cada vez mais complexos, levando-as a apresentarem características distintivas de outras empresas (MOREIRA, 2012).

Para manter-se no mercado é necessário uma visão diferente daquela do passado, onde durante muito tempo a melhoria da qualidade foi associada ao aumento de custos. Porém, quando se tem um aumento significativo na qualidade, consegue-se um aumento na produtividade e relativos ganhos. Os custos da qualidade, são decorrentes da falta de qualidade. As falhas podem ser classificadas quanto: custos de prevenção (identificação de problemas potenciais com os processos e produtos), de avaliação (checagem de erros durante e após a fabricação do produto), de falhas internas (defeitos e falhas ocorridos nos produtos ainda na fábrica) e de falhas externas (resultantes de problemas após a entrega dos produtos no mercado (OLIVEIRA et al., 2004).

Este trabalho tem como objetivo mostrar a aplicação da metodologia MASP para encontrar e solucionar os problemas observados após a realização dos inventários mensais, tendo como foco, por meio das ferramentas da gestão da qualidade (brainstorming, diagrama de Ishikawa, diagrama de Pareto, 5 porquês, estratificação e $5 \mathrm{~W} 1 \mathrm{H})$ a redução das perdas nas matériasprimas presentes nas composições dos derivados de tomate.

\section{Referencial teórico}

\subsection{Gestão da qualidade}

O gerenciamento estratégico da qualidade, visa através do controle de qualidade manter as empresas competitiva no mercado, mas acima de tudo conseguir satisfazer as necessidades e 
expectativas do cliente. Para alcançar o nível de qualidade esperado, o produto precisa reunir alguns aspectos na sua performance, como: durabilidade, confiabilidade, precisão, facilidade de operação e manutenção. Através do planejamento e sistematização de todos os processos dentro da empresa é possível ter a garantia da qualidade, porém, para alcançá-la, todos dentro da organização deve pensar e agir com a filosofia de defeito zero (MACHADO, 2012).

Segundo Oliveira et al. (2004), dentro das empresas é possível identificar diversas atividades mal dimensionadas, podendo ser totalmente eliminadas ou rearranjadas através de ferramentas de gestão da qualidade que prevê a eliminação ou até mesmo a simplificação de processos, com a finalidade de agregar valor ao produto. Com a utilização destas ferramentas é possível gerir, controlar e otimizar os processos já existentes dentro da empresa.

\subsection{MASP (Metodologia de Análise e Solução de Problemas)}

A metodologia MASP surge pela necessidade do gerenciamento de processos que não se encontram dentro dos padrões estipulado pela organização. O MASP é visto como uma estratégia para atacar e solucionar o problema a partir de um ciclo de etapas inerente ao ciclo PDCA e ferramentas da qualidade. As etapas a serem seguidas pela metodologia são: identificar o problema; observar e coletar dados; analisar as causas; estabelecer um plano de ação; realizar as ações estabelecidas; verificar; padronizar e concluir (BASSAN, 2018).

"A metodologia permite identificar e estabelecer parâmetros para a análise de problemas até a observação da solução, a qual, ao se integrar com as ferramentas, permite a aplicação prática do método" (SELEME; STADLER, 2012, p.31).

Figura 1 - Ciclo MASP

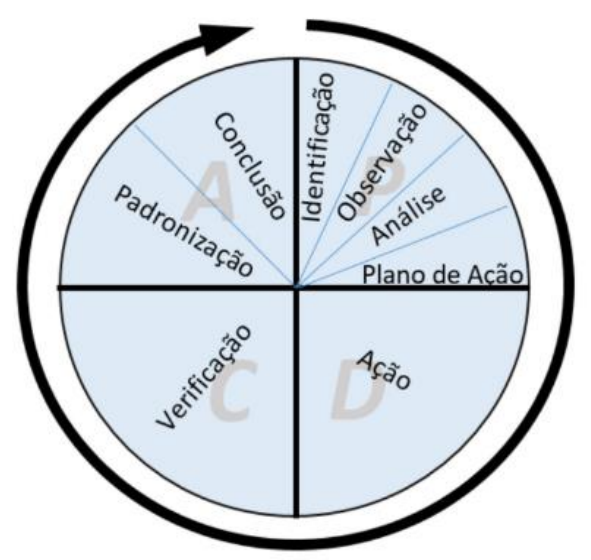

Fonte: Bassan (2018) 


\subsection{Gráfico de pareto}

O gráfico de Pareto, também chamado de “diagrama", é uma ferramenta de qualidade desenvolvida por Joseph Juran, a partir de estudos realizados pelo economista Vilfredo Pareto sobre a relação 20/80. Juran estabeleceu uma classificação dos problemas de qualidade baseada nesta relação, onde a maior quantidade dos defeitos se baseiam em poucas causas. Esse gráfico permite que sejam identificados e classificados os problemas mais importantes, e com maior senso de urgência na correção, possibilitando a empresa de usar melhor os seus recursos na melhoria da qualidade do processo e do produto (SELEME; STADLER, 2012).

\section{$2.45 W 1 H$}

A ferramenta $5 \mathrm{~W} 1 \mathrm{H}$, traduz perguntas que foram elaboradas na língua inglesa, que se iniciam com as letras $\mathrm{W}$ e $\mathrm{H}$, onde cada uma tem como objetivo gerar respostas que tornem claro o problema que virá a ser resolvido, ou até mesmo que ajudem na organização de ideias para a resolução do problema (SELEME; STADLER, 2012). A Figura 2 a seguir mostra o modelo conceitual dos $5 \mathrm{Ws}$ e $1 \mathrm{H}$.

Figura 2 - Modelo conceitual 5W1H

\begin{tabular}{|l|l|l|l|}
\hline pergunta & significado & pergunta instigadora & direcionador \\
\hline What? & O quê? & O que deve ser feito? & O objeto \\
\hline Who? & Quem? & Quem é o responsável? & O sujeito \\
\hline Where? & Onde? & Onde deve ser feito? & O local \\
\hline When? & Quando? & Quando deve ser feito? & O tempo \\
\hline Why? & Por quê? & Por que é necessário fazer? & A fazáo/o motivo \\
\hline How? & Como? & Como será feito? & O método \\
\hline
\end{tabular}

Fonte: Adaptado de Seleme e Stadler (2012)

\subsection{Estratificação}

A estratificação é uma ferramenta com grande utilização na identificação de oportunidades de melhoria na qualidade em situações em que os dados vieram de fontes diferentes, entretanto, estão agrupados da mesma forma em um mesmo banco de dados (OLIVEIRA, 2016).

A estratificação consiste em separar dados levantados em grupos distintos, tais como: estratificação por local, por data, por turno, por tipo e assim por diante. A estratificação permite analisar os dados separadamente para descobrir onde realmente está a verdadeira causa de um 
problema (PEINADO; GRAEML, 2007). A Figura 3 a seguir mostra um exemplo gráfico de estratificação.

Figura 3 - Gráfico estratificado

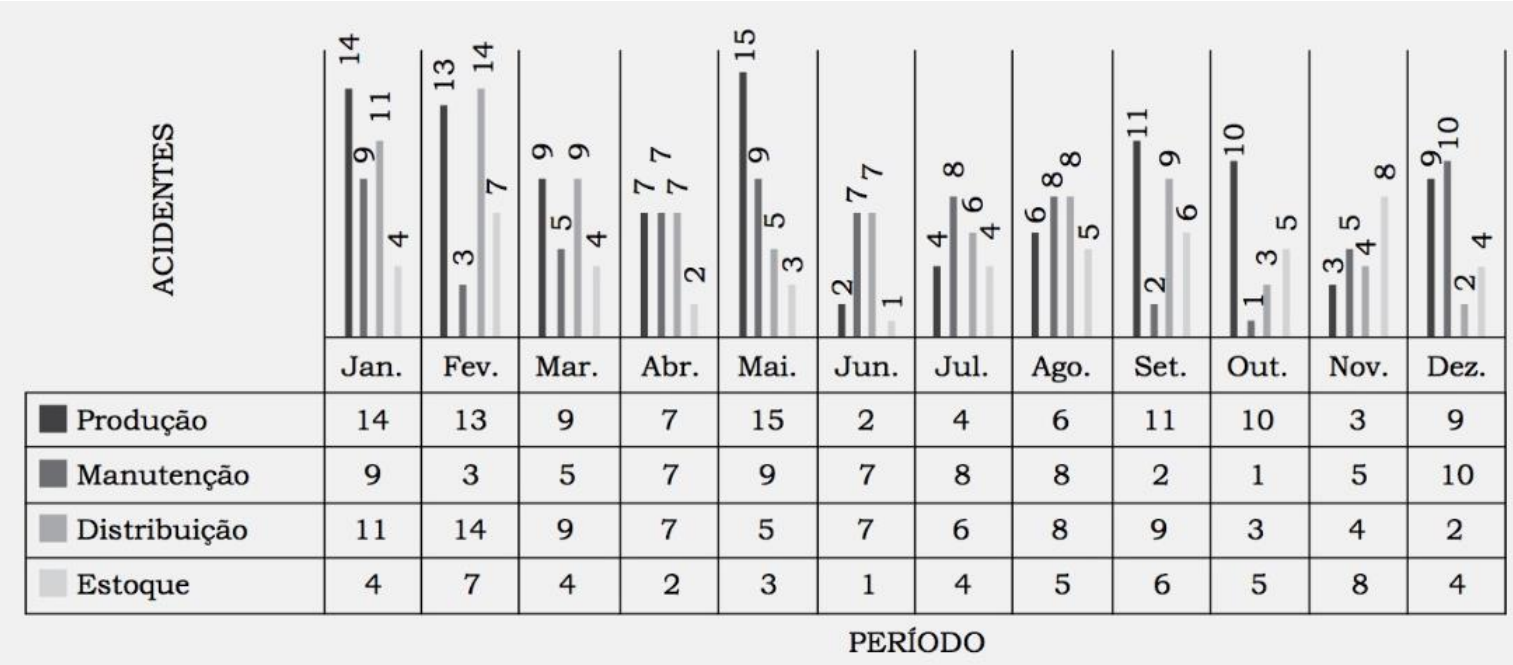

Fonte: Oliveira (2014)

\subsection{Brainstorming}

O brainstorming ou "tempestade de ideias", em tradução literal, é uma ferramenta utilizada em reuniões com um grupo de pessoas para se obter o máximo de ideias sobre determinado assunto, com objetivo de trazer à tona inspiração a partir das ideias que venham surgindo durante a reunião. (PEINADO; GRAEML, 2007).

"O brainstorming é considerado três fases distintas. A primeira é aquela em que as ideias são geradas, a segunda é destinada a realização dos esclarecimentos relativos ao processo, e a terceira presta-se à avaliação das ideais propostas" (SELEME; STADLER, 2012, p.56).

\subsection{Diagrama de causa e efeito}

O diagrama de causa e efeito é conhecido também por diagrama de Ishikawa ou espinha de peixe devido sua representação gráfica, que auxilia na identificação, exploração e apresentação das possíveis causas de uma situação ou problema específico. Estas possíveis causas mostram hipóteses que devem ser analisadas e testadas uma a uma, com objetivo de provar sua veracidade e determinar o grau de influência ou impacto sobre a situação em análise. Essas possíveis causas geralmente são levantadas em uma sessão de brainstorming. Nessa situação, o 
diagrama de causa e efeito estimula a participação das pessoas na análise de problemas (PEINADO; GRAEML, 2007).

A análise é feita a partir dos 6’Ms, que representa, matérias, máquina, mão de obra, método, meio ambiente e medida, que são os aspectos que caracterizam as causas ou ações que produzem os efeitos (SELEME; STADLER, 2012). A Figura 4 a seguir mostra um exemplo do diagrama de causa e efeito.

Figura 4 - Diagrama de causa e efeito

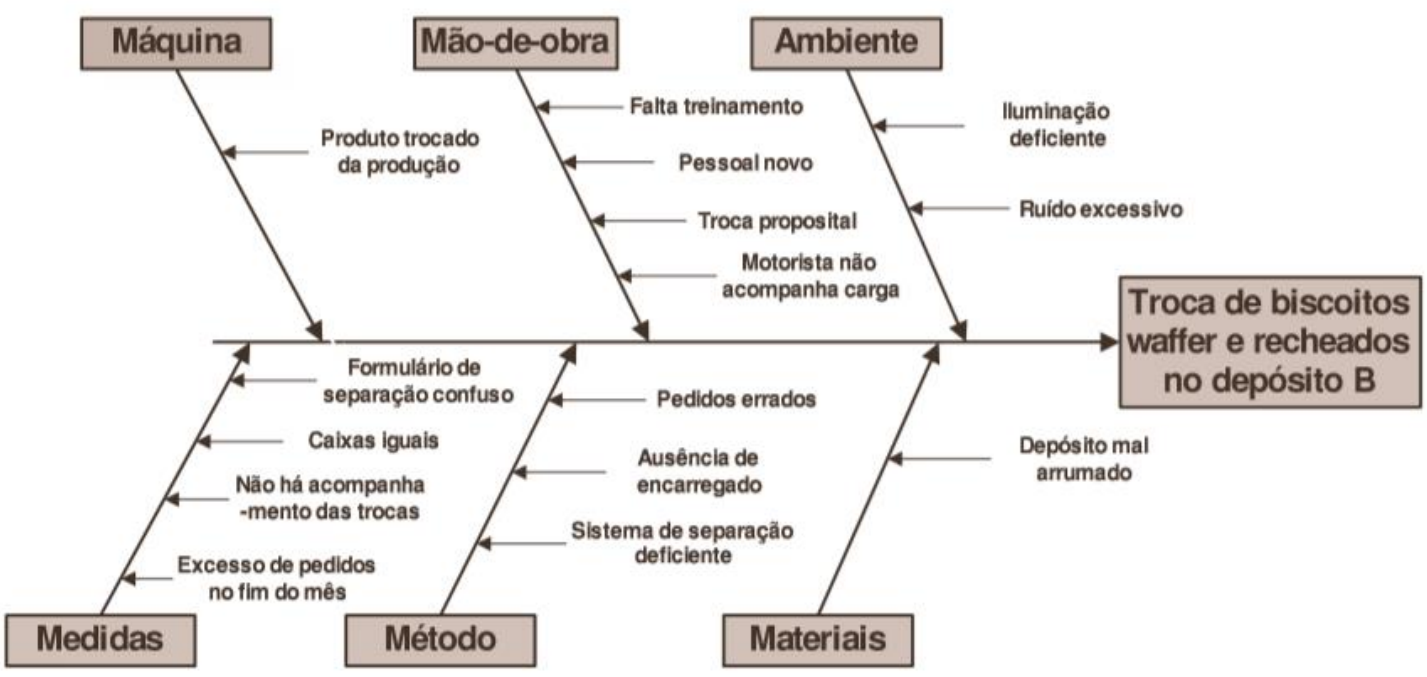

Fonte: Peinado e Graeml (2007)

\subsection{5 porquês}

A análise de Cinco Porquês é uma ferramenta eficiente, simples e muito utilizada para a compreender e investigar a causa raiz de uma situação ou defeito. Essa análise consiste em perguntar cinco vezes o porquê de uma situação ou circunstância, de forma analítica, metodológica e registrada. Criada no Japão é muito usada pelos profissionais das áreas da qualidade, esta ferramenta pode ter diversas aplicações em vários setores e situações (BASSAN, 2018). A Figura 5 abaixo mostra um exemplo de quadro 5 Porquês. 
Figura 5 - Modelo para aplicação de 5 Porquês

\begin{tabular}{|c|c|c|c|c|c|}
\hline PROBLEMA & POR QUE? & POR QUE? & POR QUE? & POR QUE? & POR QUE? \\
\hline & & & & & \\
\hline & & & & & \\
\hline & & & & & \\
\hline & & & & & \\
\hline & & & & & \\
\hline & & & & & \\
\hline & & & & & \\
\hline
\end{tabular}

Fonte: Bassan (2018)

\section{Metodologia}

A pesquisa científica objetiva entender um ou mais pontos cientificamente de determinado assunto e sua abordagem apresenta identificação sistemática, metódica e crítica. Quanto a sua classificação, pode ser determinada pelo seu ponto de vista da natureza; seus objetivos; procedimentos técnicos e abordagem do problema (PRODANOV E FREITAS, 2013). Esse artigo tem sua classificação definida como pesquisa aplicada, exploratória, de estudo de caso com desenvolvimento quantitativo e qualitativo.

Segundo Yin (2001), o estudo de caso é aplicado para examinação de ocorrências recentes, mas que não haja a modificação de procedimentos das mesmas. A técnica da pesquisa histórica é bastante utilizada dentro do estudo de caso, mas também é necessário fazer uso de observação direta e de entrevistas ordenadas em sequência. Apesar do estudo de caso ter sua semelhança com a pesquisa história, a mesma se diferencia pela sua extensa habilidade em estudar variados indícios de documentos, artefatos, entrevistas e observações.

O estudo de caso em questão foi realizado em uma indústria alimentícia considerada de médio porte, localizada do agreste pernambucano, com capacidade de produção de até 2.500 toneladas por mês. Para atingir o objetivo deste estudo, que é a redução das perdas com foco nas matériasprimas presente nas composições dos derivados de tomate, será utilizado o método MASP que é uma metodologia estruturada e sistematizada, contendo 8 etapas com uma abordagem reativa, possibilitando a tomada de ações corretivas e preventivas, as atividades realizadas podem ser verificadas na Figura 6 abaixo. Com o intuito de analisar o problema em questão, construiu-se 
planilhas para cada etapa do estudo utilizando o software Microsoft Excel e suas ferramentas, em relação ao acompanhamento das atividades foi necessário o uso de cronômetro, papel e caneta. Para realizar o estudo do nível de acidez do vinagre do seu armazenamento até sua utilização, foi necessário o uso de um medidor de acidez e uma geladeira.

Figura 6 - Etapas do MASP

\begin{tabular}{|c|c|c|}
\hline FLUXO & ETAPAS & ATIVIDADES REALIZADA \\
\hline & Identificação do problema & $\begin{array}{l}\text { A partir da observação de cada inventário mensal foi detectado a ocorrência de perdas de } \\
\text { determinados tipos de matérias-primas. Nessa etapa o gráfico de Pareto foi essencial na } \\
\text { priorização da perda a ser tratada. }\end{array}$ \\
\hline & Observação & $\begin{array}{l}\text { O vinagre foi a matéria-prima com maior percentual de perda, para identificação da sua } \\
\text { causa raiz foi necessário fazer a observação de como é realizada as atividades de } \\
\text { recebimento, armazenagem, transporte e mistura do vinagre. Foi necessário também a } \\
\text { realização de testes diário para medir o nível de acidez do vinagre. }\end{array}$ \\
\hline & Análise & $\begin{array}{l}\text { Foi realizada uma reunião com um operador, um auxiliar, um supervisor de produção, um } \\
\text { encarregado e um analista de processos para realização de um Brainstorming sobre as } \\
\text { possíveis causas da perda do vinagre e seu eventual efeito. }\end{array}$ \\
\hline & Plano de ação & $\begin{array}{l}\text { A partir da análise de todas as causas apontadas, foi possível montar o plano de ação na } \\
\text { tratativa dos gargalos encontrado. Para a construção do plano de ação foi construído uma } \\
\text { planilha com as contramedidas, quem realizaria essa atividade, o prazo para realização e } \\
\text { status da ação. }\end{array}$ \\
\hline & Ação & $\begin{array}{l}\text { Após a validação das ações, as contramedidas começaram a ser realizadas de acordo com } \\
\text { a planilha de ação. }\end{array}$ \\
\hline & Verificação dos resultados & $\begin{array}{l}\text { Para verificar se as medidas de ação foram suficientes, a cada mês o inventário de perda de } \\
\text { matéria-prima foi verificado. }\end{array}$ \\
\hline & Padronização & $\begin{array}{l}\text { Para padronização das ações será feito um POP para o recebimento e armazenagem do } \\
\text { produto, um POP para a análise da acidez do vinagre e um outro POP sobre a } \\
\text { homogenização do vinagre nas receitas de atomatados. }\end{array}$ \\
\hline & Conclusão & $\begin{array}{l}\text { Foi notório a redução da perda no percentual de vinagre e na sua manipulação pelos } \\
\text { colaboradores. }\end{array}$ \\
\hline
\end{tabular}

Fonte: As autoras (2020)

\section{Estudo de caso}

O cenário objeto deste estudo foi uma indústria considerada de médio porte, que conta com cerca de 270 funcionários, com a produção e setores auxiliares funcionando nos 3 turnos e com capacidade de produção de até 2.500 toneladas por mês. A empresa conta com 7 linhas de produção, 2 linhas de moagem de frutas e uma linha de envase asséptico de polpas. Seu portfólio é diversificado, abrangendo desde derivados de tomate, doces em massa até sucos de frutas concentrados. Em relação à estrutura física, a empresa possui ainda um setor agrícola, a expedição, a oficina de manutenção, o almoxarifado e todo o setor administrativo. A unidade conta com uma área total de $120.000 \mathrm{~m}^{2}$, sendo $18.000 \mathrm{~m}^{2}$ de área construída composta por linhas de produção, sistema de geração a vapor e tratamento d'água e de efluentes. Neste cenário 
foi observado no inventário mensal que ocorriam variações entre as quantidades de insumos utilizadas e as previstas para as produções tendo como consequência perdas financeiras. Com isso o objetivo deste estudo foi a redução das perdas com foco nas matérias-primas e embalagens das linhas de atomatados, que somam aproximadamente $70 \%$ da relação de seus produtos.

\subsection{Identificando o problema}

Neste passo foi realizado a identificação do problema que será abordado, foram utilizadas as ferramentas de qualidade e com base nos dados coletados foi feito a priorização dos gargalos. Este passo foi fundamental para o andamento e determinação das metas do estudo de caso.

O Gráfico de Pareto foi essencial na priorização da perda a ser tratada. Conhecido como diagrama 80/20, foi possível encontrar o gargalo mais determinante em relação aos outros. $\mathrm{Na}$ Figura 7, onde pode-se observar as principais perdas de insumos das linhas de produção.

Figura 7 - Gráfico de Pareto com as principais perdas do mês de fevereiro/2020

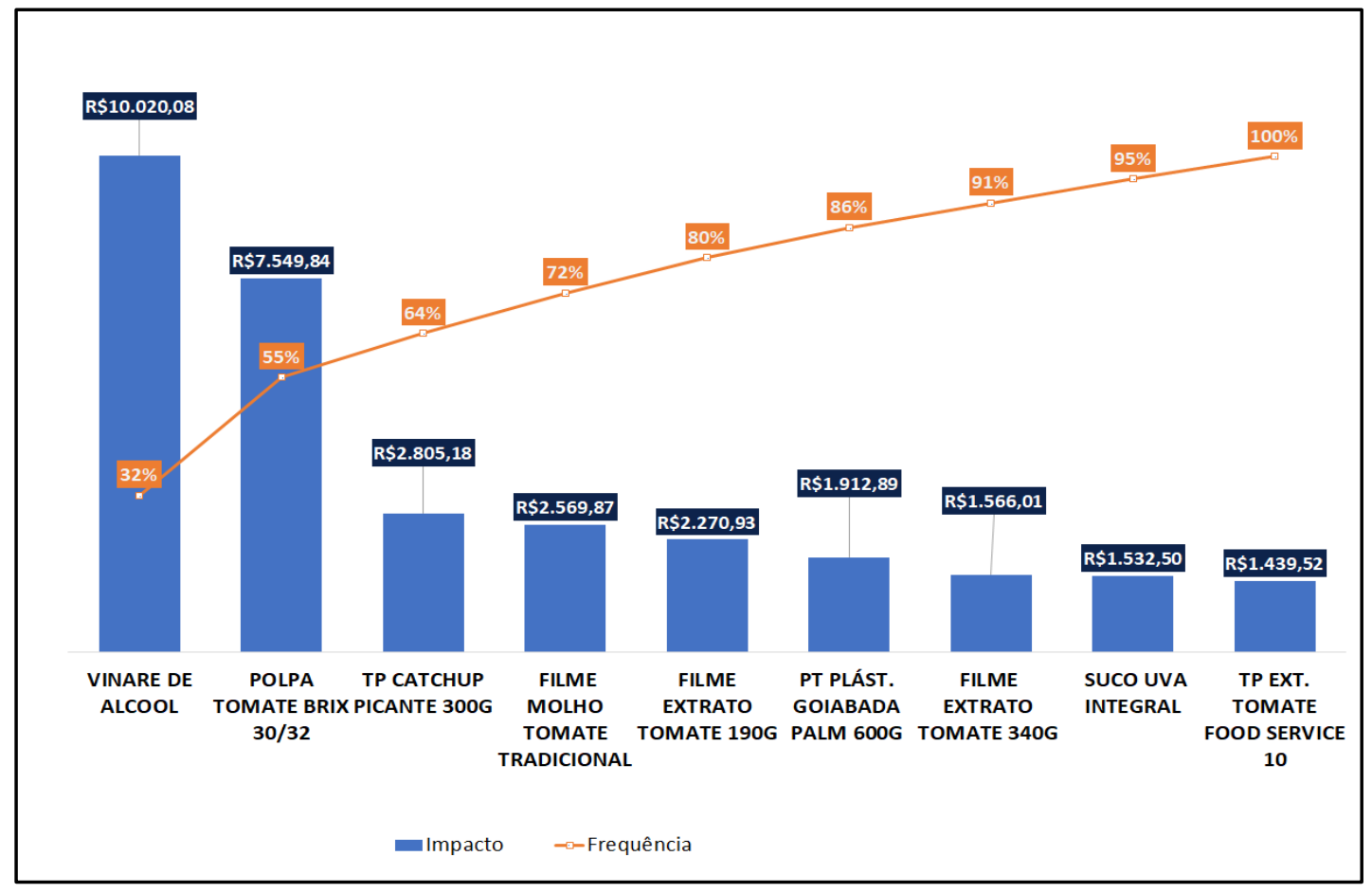

Fonte: As autoras (2020)

Analisou-se que o percentual de perda de vinagre representa em torno de $32 \%$ do total das perdas de insumos referente a linhas de atomatados. Com isso o vinagre foi a matéria-prima escolhida para ter seu desperdício tratado com o uso das ferramentas de qualidade. 
A próxima ferramenta utilizada nesta etapa foi o $5 \mathrm{~W} 1 \mathrm{H}$, que foi usado com o intuito de fazer uma descrição minuciosa do problema, sendo assim identificando onde, quando, o que, quem, porque e como aquele gargalo acontece. No Quadro 1 abaixo segue a ferramenta sendo aplicada.

Quadro 1 - 5W1H na identificação da causa

\begin{tabular}{|c|c|c|c|c|c|}
\hline O que? & Onde? & Quando? & Quem? & Porque? & Como? \\
\hline $\begin{array}{c}\text { Consumo } \\
\text { excessivo de } \\
\text { vinagre }\end{array}$ & $\begin{array}{c}\text { Na preparação de } \\
\text { atomatados }\end{array}$ & $\begin{array}{c}\text { Ocorre nos três } \\
\text { turnos de } \\
\text { produção, durante } \\
\text { a preparação }\end{array}$ & $\begin{array}{c}\text { O problema está } \\
\text { relacionado com a } \\
\text { maneira que os } \\
\text { atomatados são } \\
\text { preparados }\end{array}$ & $\begin{array}{c}\text { Para a redução do } \\
\text { consumo } \\
\text { excessivo de } \\
\text { vinagre na } \\
\text { preparação de } \\
\text { atomatados }\end{array}$ & $\begin{array}{c}\text { Atualmente o } \\
\text { percentual de } \\
\text { perda de vinagre } \\
\text { está em torno de } \\
\text { ideal seria de } 1 \%\end{array}$ \\
\hline
\end{tabular}

Fonte: As autoras (2020)

Sendo assim a ferramenta aplicada trouxe a certeza de que o problema está na linha de atomatados, na fase de preparação das receitas, ocorrendo nos três turnos e está relacionado com a maneira que a receita é preparada.

\subsection{Observando o problema}

Fazer a observação do problema no GEMBA, foi o início da segunda etapa sendo possível olhar sob várias perspectivas o processo tentando entender como acontece o gargalo. Neste passo foi necessário o envolvimento dos colaboradores que estão diretamente ligados à área afetada, sendo eles operadores e auxiliares de produção, mas também se torna importante a colaboração de pessoas que não estejam vivenciando o dia-a-dia do processo para que oportunidades não sejam perdidas pela não percepção de erros corriqueiros.

O próximo passo foi feito a estratificação para fazer uma análise separada dos dados com o intuito de descobrir a real causa do problema. Com a definição do problema central feita no passo anterior, agora foi necessário observar a fonte de todas as possíveis causas que podem ocasioná-lo. Uma das causas foi identificada a partir de dados de perdas de vinagre durante todo o ano de 2019, como mostra a Figura 8, na qual foi necessário fazer um estudo mais aprofundado e detalhado para descobrir o que estava gerando o problema. 
Figura 8 - Gráfico das perdas mensais de vinagre em 2019

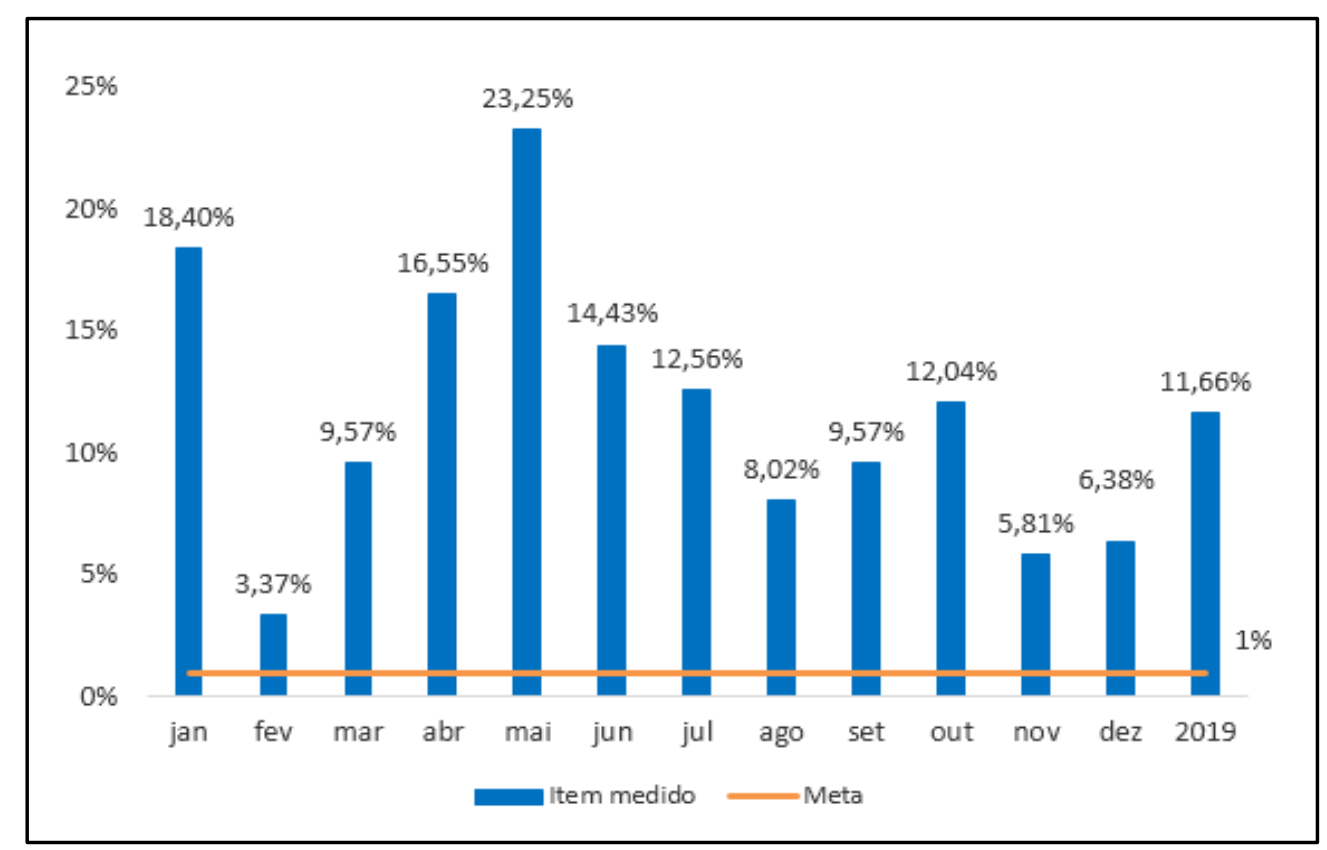

Fonte: As autoras (2020)

Observando, mais a fundo, percebeu-se que um possível ponto que influenciou nesta perda foi a acidez do vinagre. Por fórmula, o grau de acidez necessário para cada receita é $8,5 \%$, todo valor menor que isso gera como consequência um acréscimo da matéria-prima na preparação da receita. Sendo assim, foi feito um estudo testando laboratorialmente a acidez todos os dias. Na Figura 9 abaixo é possível observar os valores da acidez nos testes diários.

Figura 9 - Teste de percentual de acidez

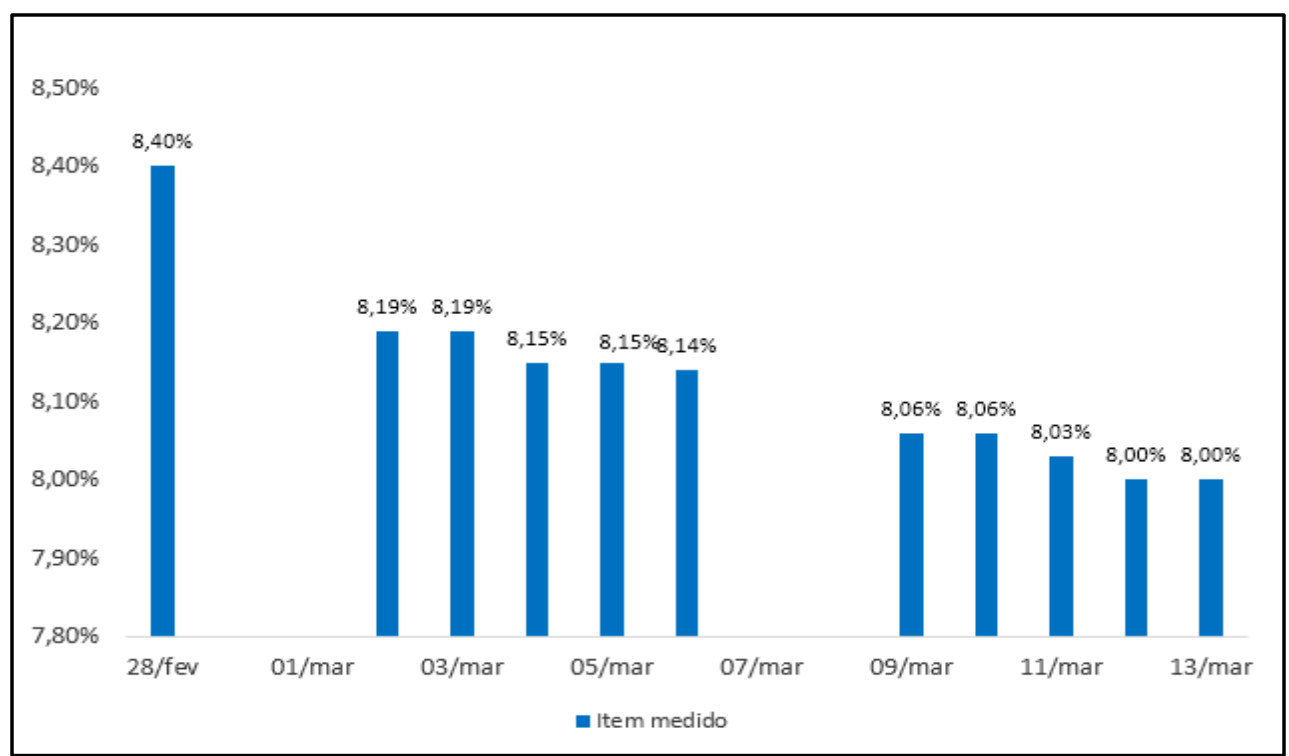

Fonte: As autoras (2020) 
Nesses testes foi possível observar que a empresa já recebia a matéria-prima com especificação menor que solicitada e que no recebimento e armazenamento ocorriam erros que acarretavam um índice de acidez menor a cada dia.

\subsection{Análise do problema}

Sendo uma das etapas mais cruciais do processo de tratamento de gargalos, neste ponto são listadas as possíveis causas do problema, feito a comprovação delas e a análise até chegar na causa raiz.

O próximo passo foi a realização de uma reunião com as pessoas envolvidas no processo e a discussão do problema, todos foram incentivados a explanarem sobre suas ideias acerca de possíveis causas que poderiam gerar o problema. No Quadro 2 abaixo é possível ver as causas listadas pelos que estavam presentes na reunião.

Quadro 2 - Brainstorming com as possíveis causas

\begin{tabular}{|c|c|}
\hline $\mathbf{N}^{\mathbf{0}}$ & $\begin{array}{c}\text { Relação de causas que podem estar } \\
\text { provocando o problema }\end{array}$ \\
\hline 1 & Mal fechamento das bombonas \\
\hline 2 & Correção de receitas \\
\hline 3 & Temperatura \\
\hline 4 & Perda de MP no abastecimento \\
\hline 5 & Variação da preparação da receita \\
\hline 6 & Desperdício na execução da receita \\
\hline 7 & Falta de padronização nas receitas \\
\hline
\end{tabular}

Fonte: As autoras (2020)

Ao término da reunião, foi feito a comprovação das causas e sendo elas verdadeiras foi feito a utilização no diagrama de causa e efeito. Das causas citadas acima seis foram confirmadas como verdadeiras.

Com o brainstorming foi levantado possíveis causas que foram levadas para o diagrama de causa e efeito onde foi utilizado os 4m's: método, mão de obra, meio ambiente e matéria prima. A Figura 10, a seguir, mostra quais causas que foram confirmadas para investigação mais profunda. 
Figura 10 - Diagrama de causa e efeito com causas comprovadas

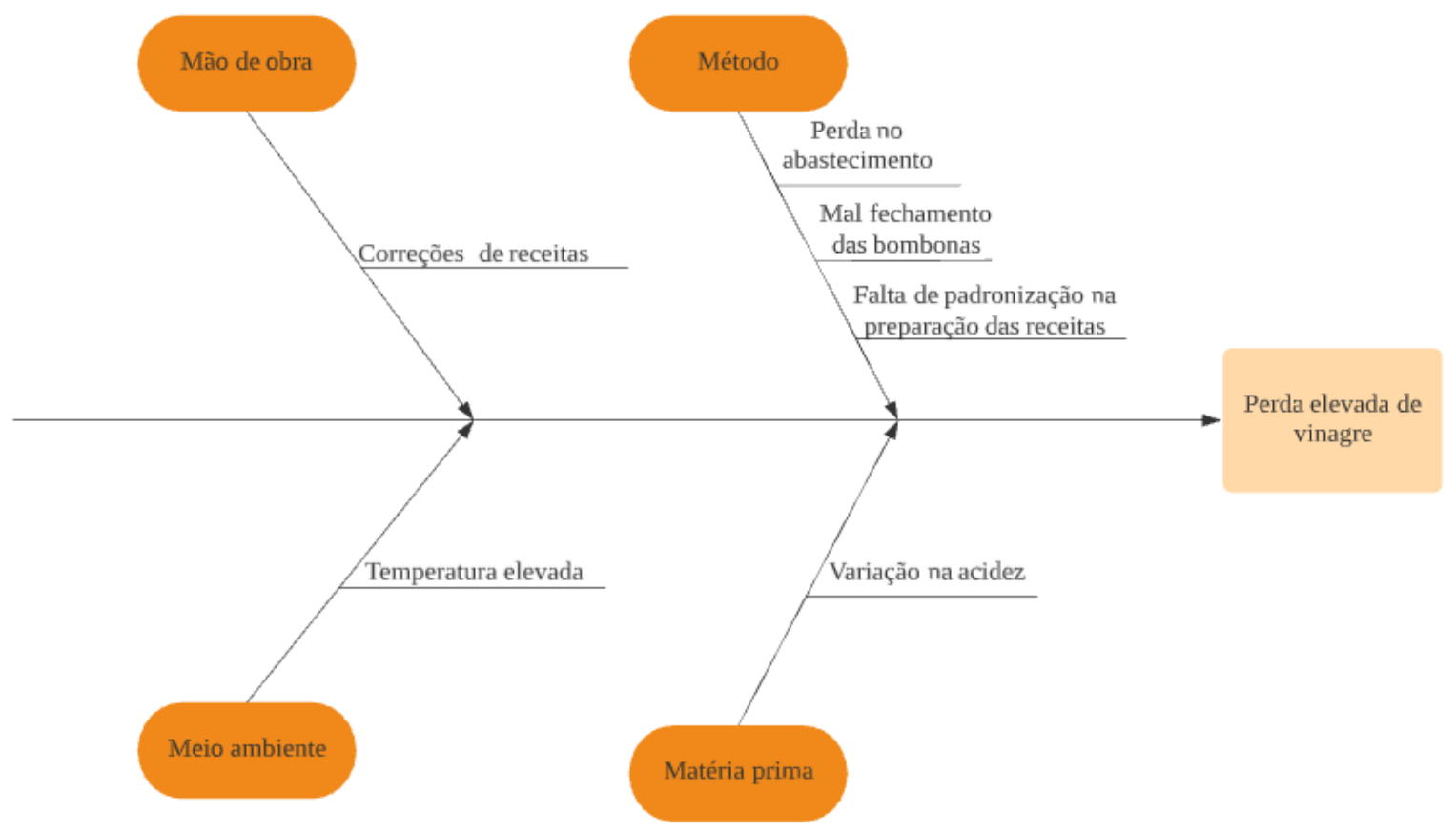

Fonte: As autoras (2020)

Das causas citadas algumas foram identificadas como Ver e Agir, que são ações corretivas mais rápidas de realizar, onde não há necessidade de investigação dos porquês e as demais foram investigadas.

Os 5 porquês foram utilizados com o propósito de aprofundar o problema até encontrar a causa real do mesmo. Foi realizado as perguntas até fazer sentido para todos presentes na reunião, como mostra a Figura 11 abaixo.

Figura 11 - 5 porquês com as causas encontradas

\begin{tabular}{|c|c|c|c|c|}
\hline EFEITO & Porque? & Porque? & Porque? & Porque? \\
\hline \multirow[t]{2}{*}{$\begin{array}{l}\text { PERDA ELEVADA } \\
\text { DE VINAGRE }\end{array}$} & $\begin{array}{l}\text { Ocorre perda no } \\
\text { abstecimento }\end{array}$ & $\begin{array}{c}\text { Derrama vinagre no } \\
\text { momento que troca o } \\
\text { mangote de uma } \\
\text { bombona para outra }\end{array}$ & $\begin{array}{l}\text { O mangote está sem a } \\
\text { válvula de abertura }\end{array}$ & $\begin{array}{l}\text { A válvula quebrou e } \\
\text { não foi trocada }\end{array}$ \\
\hline & Portanto & Portanto & Portanto & Portanto \\
\hline EFEITO & Porque? & Porque? & Porque? & Porque? \\
\hline \multirow[t]{2}{*}{$\begin{array}{l}\text { PERDA ELEVADA } \\
\text { DE VINAGRE }\end{array}$} & $\begin{array}{l}\text { Ocorre falta de } \\
\text { padronozação na } \\
\text { preparação das } \\
\text { receitas }\end{array}$ & $\begin{array}{l}\text { Cada preparador } \\
\text { coloca a quantidade } \\
\text { que acha correta }\end{array}$ & $\begin{array}{c}\text { Não houve } \\
\text { treinamento sobre a } \\
\text { formulação de cada } \\
\text { produto }\end{array}$ & $\begin{array}{l}\text { Nos últimos anos } \\
\text { ocorreram muitas } \\
\text { mudanças nas } \\
\text { formulações }\end{array}$ \\
\hline & Portanto & Portanto & Portanto & Portanto \\
\hline
\end{tabular}

Fonte: As autoras (2020) 
Nesta análise foi possível identificar qual das causas raízes influenciaram mais nesse problema. Sendo assim, foi determinado que a válvula quebrada e as mudanças de formulação foram cruciais no problema.

\subsection{Plano de ação}

Foram feitas análises a partir do diagrama de causa e efeito e montado o plano de ação para as tratativas das causas. Segue abaixo toda a análise:

- Perda no abastecimento: é utilizado um mangote preso no caminhão que enche tambores de um por um e existe uma válvula no final para fechar e poder passar para outro tambor, foi então identificado que essa válvula estava quebrada a algum tempo e ninguém fez o reparo ou troca por uma nova, e ao passar de um tambor para outro derramava muito.

- Mal fechamento do tambor: foi observado e checado cada tambor e verificou que de fato os tambores estavam mal fechados e que facilitava a evaporação do vinagre.

- Variação da acidez: por formulação o vinagre utilizado tem que ter uma média de acidez de $8,5 \%$, qualquer valor abaixo gera perda pois é necessário colocar em maior quantidade para ajustar a acidez. Foram feitas várias análises do vinagre, todos os dias, nos mesmos horários, na mesma temperatura e todos os dias a acidez foi diferente.

- Falta de padronização na preparação das receitas: foi observado que os preparadores quando estão fazendo a receita colocam a quantidade de vinagre que acham adequadas pois as fórmulas já foram modificadas muitas vezes nos últimos anos e eles não foram treinados com a nova formulação.

- Correção da receita: foi observado que os preparadores quando estão fazendo a receita não deixam tempo para o vinagre concentrar, só jogam no tanque de preparação, mexem e levam para análise, que aponta a baixa acidez, então eles aumentam a quantidade de vinagre em vez de homogeneizar a receita.

- Temperatura elevada: os tambores são armazenados à temperatura ambiente o que pode causar a evaporação do vinagre, caso as tampas estejam meio abertas. 
Com essa análise foi possível montar um plano de ação, para facilitar as especificações das tratativas dos gargalos. Como mostra o Quadro 3 abaixo, onde pode-se encontrar todas as informações.

Quadro 3 - Plano de ação

\begin{tabular}{|c|c|c|c|c|}
\hline CAUSAS-RAIZ & CONTRAMEDIDAS & QUEM & PRAZO & STATUS \\
\hline \multirow{2}{*}{ Variação na acidez } & Teste com vinagre sob refrigeração & Qualidade & $08 / 03 / 2020$ & Concluído \\
\hline & Solicitar ao fornecedor ajuste na acidez & Qualidade & $09 / 03 / 2020$ & Concluído \\
\hline Perda no abastecimento & $\begin{array}{l}\text { Restauração do mangote de enchimento } \\
\text { dos tambores }\end{array}$ & Almoxarifado & $15 / 03 / 2020$ & Concluído \\
\hline $\begin{array}{c}\text { Mal fechamento dos } \\
\text { tambores e temperatura } \\
\text { elevada }\end{array}$ & Inspeção na término do descarregamento & Almoxarifado & $\begin{array}{l}\text { A cada } \\
\text { carregamento } \\
\text { novo } \\
\end{array}$ & Contínuo \\
\hline $\begin{array}{l}\text { Falta de padronização na } \\
\text { preparação e correção de } \\
\text { receitas }\end{array}$ & $\begin{array}{c}\text { Treinamento com as novas formulações, } \\
\text { frisando a importância da } \\
\text { homogeinização correta }\end{array}$ & Qualidade & $15 / 03 / 2020$ & Concluído \\
\hline
\end{tabular}

Fonte: As autoras (2020)

\subsection{Resultados}

Com o início do plano de ação colocado em prática já foi possível observar melhorias nos processos onde foram encontrados os gargalos. No inventário do mês de março foi visto uma redução no percentual de variação e como consequência no valor do desperdício. Abaixo, podese notar a diferença de percentuais nos últimos meses.

Figura 12 - Gráfico de perdas mensais do ano de 2020

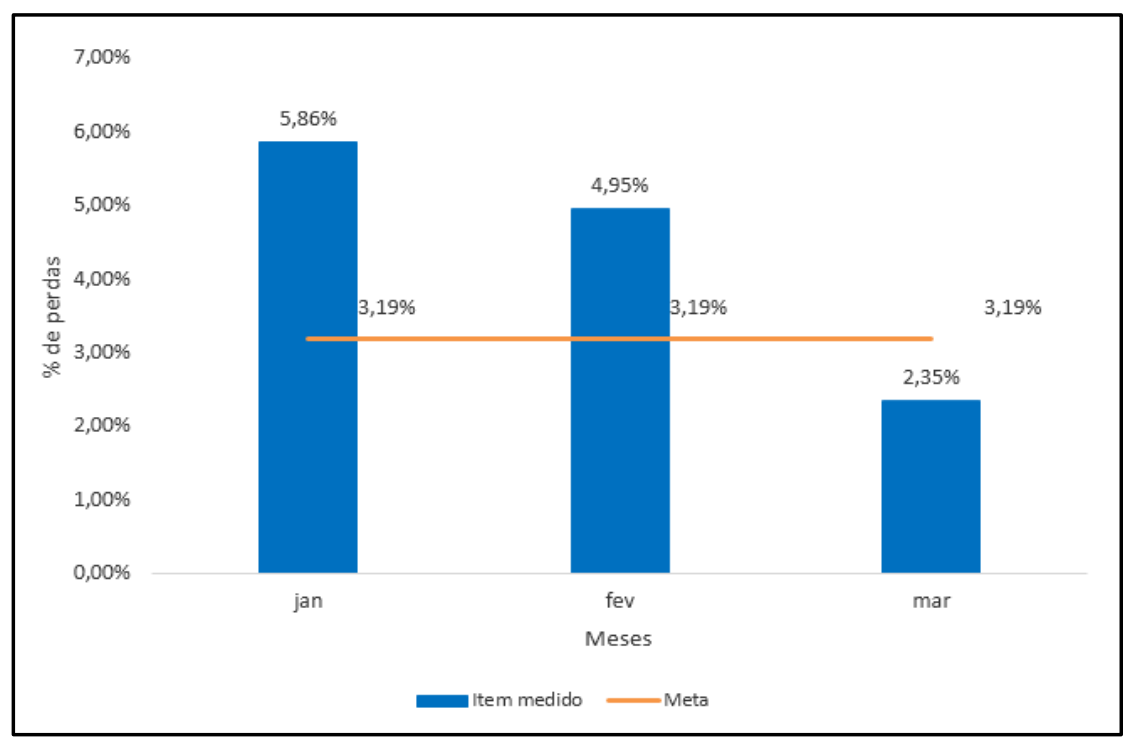

Fonte: As autoras (2020) 
Na Figura 9 acima, percebe-se que houve uma redução de mais de 50\% em relação ao mês de fevereiro. Sendo assim, as ações propostas no plano de ação foram eficazes tornando possível a validação de toda a investigação do problema.

\section{Conclusão}

Neste trabalho constatou-se que a utilização da metodologia MASP foi uma importante estratégia usada para estruturar, atacar e solucionar problemas referentes às perdas nas matériasprimas presentes nas composições dos derivados de tomate. Para tal utilizou-se diversas ferramentas da gestão da qualidade.

Com o gráfico de Pareto foi identificado que a perda de vinagre além de possuir maior impacto financeiro constituía o maior gargalo, totalizando $32 \%$ do número total de perdas, tornando-o, portanto, o problema central para o estudo de caso. Em seguida foi aplicada a ferramenta $5 \mathrm{~W} 1 \mathrm{H}$, e identificou-se que o problema estava acontecendo na linha de atomatados na fase de preparação das receitas.

Afim de compreender melhor a problemática, após a identificação do maior gargalo, iniciou-se a fase de observação, análise e estratificação dos dados, verificando que um dos problemas possíveis era a acidez que por vezes era menor que o necessário de $8,5 \%$ por esse motivo era utilizada mais matéria prima do que o ideal. Posteriormente com auxílio do brainstorming foi levantado as possíveis causas que estão ocorrendo levando para a perda do vinagre. Com o diagrama de causa e efeito foi identificado 6 causas, algumas dessas causas foram identificadas como ver e agir, e outras seguiram para o aprofundamento do porquê estavam acontecendo, sendo assim foi aplicada a ferramenta dos 5 porquês auxiliando no plano de ação.

Após colocar o plano de ação em prática, com apenas 3 meses já foi possível ver resultados positivos, havendo uma redução gradativa ao decorrer do tempo, validando a eficácia das ferramentas utilizadas, e do plano de ação criado.

Tendo em vista o exposto neste artigo, conclui-se que o uso da metodologia MASP como direcionadora, possibilita que as ferramentas de qualidade exerçam ações corretivas e preventivas que contribuem para o alcance da meta da empresa, e dessas ações é necessário a verificação de procedimentos simples e conscientizam dos funcionários incentivados nos treinamentos para evitar as perdas nos processos e assim manter a melhoria contínua na empresa. 


\section{Referências}

Associação Brasileira da Indústria de Alimentos (ABIA). Relatório anual 2019. Disponível em <https://www.abia.org.br/vsn/temp/z2020515RelatoorioAnual2020websimples.pdf>. Acessado em 20 de maio de 2020

BASSAN, Edilberto José. Gestão da Qualidade: Ferramentas, Técnicas e Métodos. $1^{\circ}$ Ed. Curitiba Pr, 2018

EMBRAPA. Modernização conservadora da produção de tomate indústria no Brasil . Brasília, 2019. disponivel em <https://www.infoteca.cnptia.embrapa.br/infoteca/bitstream/doc/1113115/1/DOC167.pdf>. Acesso em 20 de maio de 2020

MOREIRA, Daniel Augusto. Administração da produção e operações. 2.ed. rev. e ampl. São Paulo : Cengage Learning, 2012

MACHADO, Simone Silva. Gestão da qualidade. Inhumas: IFG; Santa Maria: Universidade Federal de Santa Maria, 2012.

OLIVEIRA, Otávio J. et al. Gestão da qualidade: tópicos avançados. 1.ed. São Paulo : Cengage Learning, 2004.

OLIVEIRA, Otávio J. Gestão da qualidade, higiene e segurança na empresa [recurso eletrônico]. São Paulo, SP: Cengage, 2016.

OLIVEIRA, Otávio J. Curso básico de gestão da qualidade. 1.ed. São Paulo : Cengage Learning, 2014.

PEINADO, Jurandir; GRAEML, Alexandre Reis. Administração da produção: operações industriais e de serviços. Curitiba : UnicenP, 2007.

PRODANOV, C. C.; FREITAS. E. C. Metodologia do trabalho científico: Métodos e técnicas da pesquisa e do trabalho acadêmico. $2^{\circ}$ ed. Novo Hamburgo, Rio Grande do Sul. Feevale, 2013

SELEME, Robson; STADLER, Humberto. Controle da qualidade: As ferramentas essências. $2^{\circ}$ ed. Curitiba: Ibpex, 2012.

SLACK, Nigel; STUART, Chambers; JOHNSTON, Robert. Administração da produção. 2. ed. São Paulo: Atlas, 2002

YIN, Robert K. Estudo de caso: planejamento e métodos. 2.ed. Porto Alegre. Bookman, 2001. 